\title{
Inhibitors of T cell Activation in the Treatment of Sjögren's Syndrome
}

\section{Sabine Adler, MD \\ Peter M. Villiger, $M D^{*}$}

\author{
Address \\ *Department of Rheumatology, Immunology and Allergology, University Hospital \\ Bern, Freiburgstrasse, 3010, Bern, Switzerland \\ Email: peter.villiger@insel.ch
}

Published online: 17 July 2015

C) Springer International Publishing AG 2015

This article is part of the Topical Collection on Sjögren's Syndrome

Keywords Sjögren's Syndrome - Abatacept - T cell costimulation - Cyclosporine

\section{Opinion statement}

Given the hypothesis of an initial exogenous agent attacking/infecting ocular and oral glands in Sjögren's syndrome, we propose a primarily T cell-guided reaction with ensuing recruitment of B cells and finally resulting in auto-antibody production. From an immunological standpoint, the first clinical signs do represent established disease. Nevertheless, targeted therapy should start as early as possible, and they may target B as well as T cells. A primarily local therapy by CsA eye-drops is worthwhile applying in case of strictly ocular involvement only. Otherwise, a short cycle of leflunomide might prove efficient. If not, based on the most possibly underlying pathophysiology of $T$ and $B$ cell interaction and our own experience, a 6 -month treatment with abatacept during the early phase of disease can reach the target cells and lead to clinical improvement. In the later stages, especially in case of cryoglobulinemic vasculitis or pulmonary involvement, a B cell depletional therapy may be highly effective. Based on the available data, it would be interesting to initiate a study targeting both cellular arms of the adaptive immune system, i.e., B cell depletion with, e.g., rituximab and T cell inhibition using abatacept. Trials with alefacept have shown T cell-targeted, positive effects on exocrine gland function in a primary SS (pSS)-associated non-obese diabetic (NOD) mouse model. Whether this molecular intervention is beneficial in human disease will have to be shown.

\section{Introduction}

A recent meta-analysis of population-based studies in pSS showed estimated pooled incidence rate of around 7 per 100,000 inhabitants and a pooled prevalence of around 60 per 100,000 inhabitants, representing a rather frequent autoimmune disease [1]. 
The term Sjögren's syndrome represents two different entities: Primary SS (pSS) is regarded as an independent entity among the autoimmune-mediated connective tissue diseases. It typically affects salivary and lacrimal glands plus other mucous membranes as well as extraglandular organs, posing risks for cryoglobulinemic vasculitis and secondary lymphoma formation, mainly non-Hodgkin lymphoma (NHL). Incidence for NHL in pSS varies across countries and studies within an approximated range of with standard incidence ratios (SIR) reported from 4.9 to 18.8 [2,3]. Interestingly, in a large nationwide Taiwanese study, the higher NHL incidence was seen in female pSS patients only but not in the respective male counterparts [4]. Secondary SS describes sicca symptoms and reduced exocrine function of mainly the eyes and mouth as a complication of a given autoimmune disease other than pSS, mostly rheumatoid arthritis (RA), systemic lupus erythematosus (SLE), or systemic sclerosis. Sicca symptoms secondary to, e.g., medication and/or smoking are not regarded as a separate entity but as concomitant negatively influencing factors in any of the two Sjögren's syndromes.

Despite growing knowledge about pathogenesis, the etiology of pSS remains obscure, rendering a causative treatment impossible. Histological and serological findings, however, clearly document central roles of T as well as B cells in developing and propagating the inflammation and eventually leading to tissue destruction as found within the salivary glands [5]. Furthermore, therapies using conventional immune-suppressive drugs or biologic agents have shed light on some of the complex underlying molecular pathways.

In early disease, $\mathrm{T}$ cell infiltrates mainly consisting of $\mathrm{CD} 4+$ cells predominate glandular infiltrates whereas in later stages B cell infiltration prevails, pointing to a Th-2 driven B cell activation and recruitment in the course of disease [5]. These findings strongly suggest a central regulatory role of T cells. In line with this, Th- 1 cytokines such as interferon gamma (IFNg) and TNF-alpha have been addressed therapeutically, but with questionable success. Th-2-derived cytokines like interleukins 4, 5, and 10 have been indirectly addressed by targeting $\mathrm{B}$ cells. Yet, B cell depletion using the monoclonal antibody rituximab to target CD-20-expressing B cells was helpful in highly selected patients only [6]. Furthermore, data on the identification of CD4+ TH17 memory cells within the lymphocytic foci of SS mice models and humans point to a somewhat more complex background [7].

In contrast to many systemic autoimmune diseases which can be controlled targeting a single pathogenic pathway, pSS appears to be more resistant or more complex. One option to interfere at more than one cell type is to target the T/B cell costimulation $[8,9 \bullet]$. In this context, the CD 40 ligand plays an important role. Interference within the CD40 pathway is described to ameliorate inflammation in some disease models. In non-obese diabetic (NOD) mice as a mouse model for pSS, endogenous CD40 was expressed on either inflammatory foci of salivary glands, and as well in addition on cultured epithelial cells from SS patients. Yet, first therapeutic attempts by local administration of CD40 coupled to a human FC domain neither reduce inflammation nor improve salivary gland function [10].

Taken together, $\mathrm{T}$ cell activation-in whatever way-remains a focus of interest in the pathogenesis of pSS. We address current $\mathrm{T}$ cell-targeted medication in treating pSS and give a short outlook on possible options in the near future.

\section{Treatment}

\section{Diet and lifestyle}

Lifestyle changes might be directed towards avoiding or reducing any drynessprovoking means as smoking, low fluid intake, use of anti-depressants, and sicca-inducing anti-hypertensives as, e.g., beta-blockers and diuretics. Symptomatic relief can be achieved by tear and saliva substitutes and/or salivainducing medication. Prospectively assessing the use of drugs with frequent and/or profound side effects on saliva secretion identified more than $50 \%$ of patients taking such drugs on a regular basis. Most of the patients were not informed about correct handling of sicca problems (evaluation of the Bernese Sjögren population, data not published). 
Drug therapy in general aims at relieving symptoms of dryness and fatigue, prohibiting visual loss, avoiding and/ treating extraglandular manifestations and-if at all possible-reducing the risk for lymphoma development. Unfortunately, there is no such drug or drug combination available comprising all specific needs. Miscellaneous classes of drugs were used with various outcomes.

In this review, we focus on the use of topical and systemic T cell activation inhibitors in Sjögren's syndrome.

\section{Topical therapy}

The calcineurin inhibitors (CNI) cyclosporine A (CsA) and tacrolimus (TAC) have both been used in the therapy of SS-associated dry eye problems with partly contradictory results. A recent study evaluated topical $0.05 \%$ cyclosporine A emulsion applied for keratoconjunctivitis sicca in a dosage of one drop twice a day [11•]. All patients showed significant improvement in redness, Schirmer's test, and tear break up time during a 1-month follow-up. Initial local side effects of, e.g., burning and pain waned already 1 week after start of therapy. Overall, CsA showed consistent improvement over a 6-month period, e.g., in large phase III trials [12]. Finally, a recent consensus panel evaluation recommends CsA in SS-associated dry eyes with a level II to III evidence [13].

Evidence for topical TAC is scarce, yet, a recent prospective double-blind randomized controlled trial used $0.03 \%$ TAC in pSS in a dosage of one drop twice daily in 16 eyes with promising results and significant improvements in objective measurements for exocrine gland function [14].

Nevertheless, CNI seem effective mostly in mild to moderate local disease, outcome measures differ widely between studies, and patients with corneal lacerations appear ineligible due to possibly increased topic side effects. Patients with severe ocular dryness are reluctant to use CsA because of strong burning pain. A comparison of both CNI was performed only in dogs with dry eye symptoms favoring TAC [15].

\section{Systemic non-biologic therapy}

Introduced into organ transplantation in the 1980s, cyclosporine A as systemic therapy has been used in autoimmune diseases mainly as a T lymphocyte immunmodulatory agent with various results. Due to its immunological target of activated T cells, effects in pSS were expected. Histological studies 6 months after CsA in a dosage of $5 \mathrm{mg} / \mathrm{kg} /$ day divided into two daily applications showed decreased $\mathrm{T}$ lymphocytes and $\mathrm{T}$ helper cells in minor salivary glands yet clinical effects were described as marginal [16]. Further studies have so far not been performed until in 2015 a Chinese group demonstrated a suppression of TH-17 cell activation by CsA at concentrations of $80 \mathrm{ng} / \mathrm{ml}$ in active pSS but not in inactive pSS patients or healthy controls [17]. Unfortunately, clinical effects were not described.

Since its first use in animal models of autoimmune diseases in the 1980s and introduced into clinical use in the late 1990s, leflunomide (LEF) has been successfully prescribed to suppress autoimmune activities in RA, psoriatic arthritis, and SLE. Its use in PSS is anecdotal, few studies and case reports of LEF did not show convincing results [18-20]. Of interest is a recent publication which reports an inhibition of IFNg by LEF which was related to improvement of saliva production [21]. Thirteen early pSS patients with a mean symptom 
duration of 3.3 years received $20 \mathrm{mg}$ leflunomide daily for a 24-week period. Unfortunately, response was counted as either subjective improvement in oral and clinical symptoms measured by visual analogue scales or as amelioration in objective parameters, which-in pSS - might differ to a great extent. Nevertheless, significant increases in stimulated salivary flow were observed in 5/13 patients and correlated well with decreases of IFNg production, thus clearly supporting the Th-1-related pathogenesis. Furthermore, in 5/13 patients, leflunomide downregulated CD40 ligand-expressing cells and an increased expression of the interleukin 7-receptor (IL-7R) alpha on CD4 T cells pointing to the demonstrated correlation of, e.g., IL-7R alpha with pSS disease activity.

\section{Systemic biologic therapy}

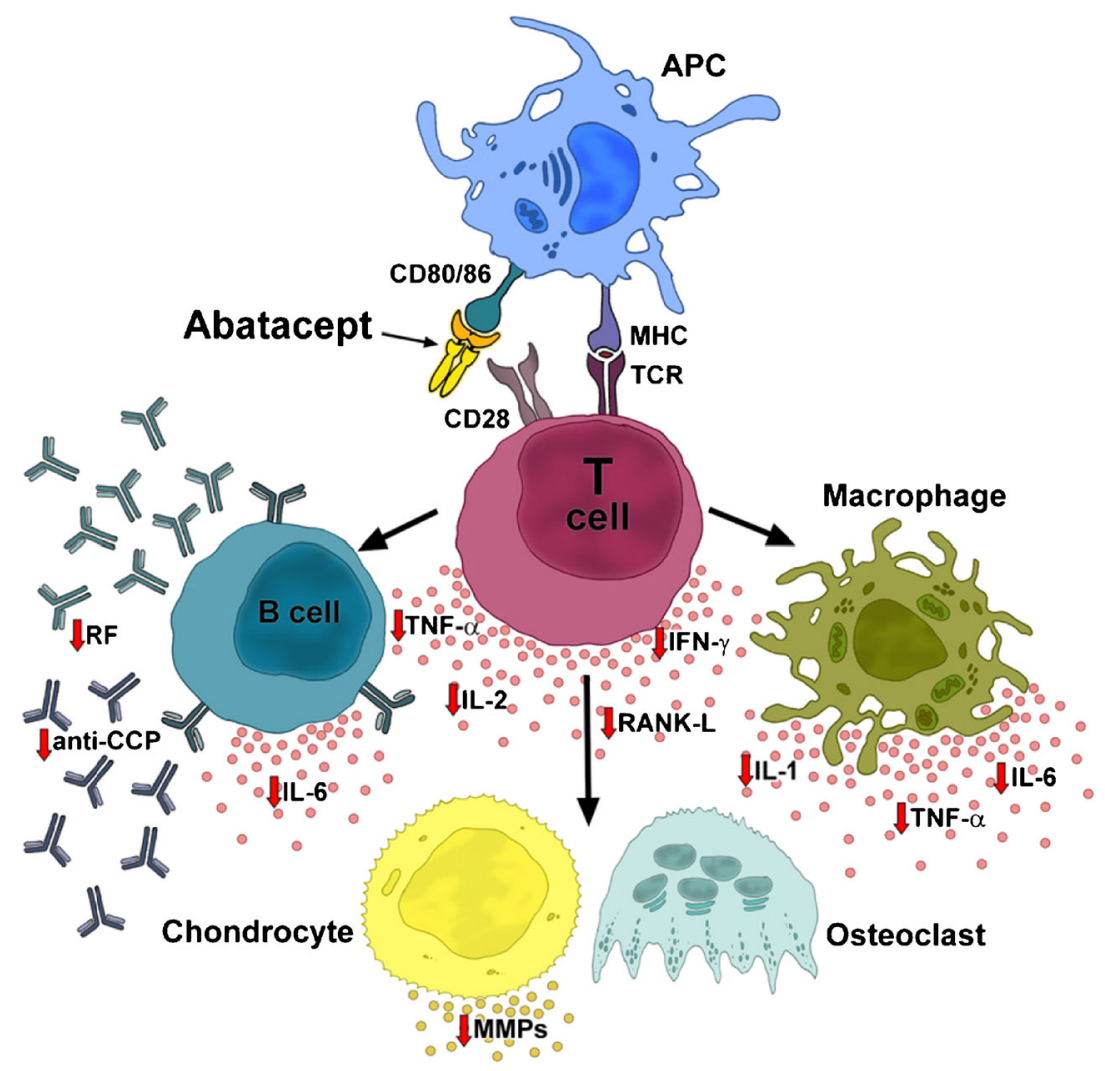

As outlined above, targeting one cell type or one mediator such as a cytokine proved not to be sufficient to induce clinically relevant improvement of salivary gland function. Inhibition of cell-crosstalk, however, bears the potential to more profoundly interfere with pathogenic events. Abatacept is a molecule which inhibits activation of $\mathrm{T}$ cells by blocking the cross talk between the antigen-presenting cell and the T lymphocyte (Fig. 1). Abatacept, primarily approved for RA treatment, represents a soluble fusion protein of the human cytotoxic T lymphocyte-associated antigen 4 linked to the modified portion of human IgG1 (CTLA4-Ig). As CTLA4 was shown to be involved in controlling CD4 proliferation and downregulating of T cell activation in SS, CTLA4-Ig

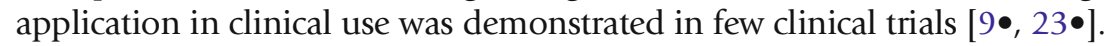

Fig. 1. Mode of action of abatacept. By binding to $\mathrm{CD} 80 / 86$, abatacept blocks the interaction of CD80/86 and CD28 on the APC and $T$ cell, respectively. The co-stimulatory pathway leading to $T$ cell activation is inhibited and processes in the inflammatory cascade are downregulated, resulting in normalized levels of cytokines and autoantibodies, and inhibition of osteoclast activity. $A P C$ antigen presenting cell (e.g., macrophages, dendritic cells, B cells), MHC major histocompatibility complex, TCR T cell receptor, $R F$ rheumatoid factor, TNF tumor necrosis factor, IFN interferon, IL interleukin, anti-CCP anti-cyclic citrullinated peptide, RANK receptor activator of NF-KB, MMPs matrix metalloproteinases [22]. 
Within the first study [4], 11 patients received RA-adapted, 8 body-weight defined doses of abatacept with pre- and post-therapy evaluations of clinical, serological, and histological parameters. Remarkably, a significant reduction in glandular inflammation could be demonstrated alongside with an increase in saliva production when adjusted for disease duration. Furthermore, a secondary effect on the B cell pool by abatacept can be assumed as naïve B cells increased at the end of the study. In another abatacept study [15] in well characterized pSS patients with short median disease duration of 11 months, the same application scheme was given, focusing on SS disease activity, SS patient-reported symptom index, and ocular and salivary gland secretion. While disease activity decreased and patient-reported symptoms ameliorated, only a slight posttreatment effect was seen regarding stimulated whole saliva production. As the study was not blinded and the read-out was patient-related, reported positive effect would have to be confirmed by a RCT. Of note, in both study groups 1 and 2, respectively, patients developed cutaneous lupus symptoms but no other side effects. Overall, abatacept proved to be a safe and valuable option to decrease pSS disease activity, demonstrate T cell changes on a structural level, and increase salivary gland function.

Several questions remain unanswered: Would higher doses or prolonged treatments lead to a histological remission with more profound effect on saliva production? Would combination therapies, e.g., targeting B and T cells lead to more rapid and substantial improvement? It is conceivable that an intensified treatment would lead to a complete remission which could be maintained using conventional doses of a single agent. These considerations have to be put into equation when it comes to discussion about cost-effectiveness. As it stands, abatacept definitely represents a cost-intensive option, yet, rituximab, displaying similar effects and more widely used, compares well.

Indirect interaction with $\mathrm{T}$ cell activation and reactivation was expected from efalizumab, a humanized monoclonal antibody targeting the CD11a component of leucocyte function-associated antigen-1 (LFA-1) and initially being approved for psoriasis, demonstrating positive effects in TNF-alpha refractory patients [24]. A possible role in controlling lymphocyte migration into exocrine glands [25] led to the initiation of an efalizumab trial in pSS patients. Started in 2006, it had to be stopped due to potential risks of progressive multifocal leucoencephalopathy [26]. In 2009, efalizumab has been withdrawn from the market completely.

Alefacept-a dimeric fusion protein-interferes with lymphocyte activation by specifically binding to the lymphocyte antigen, CD2, and inhibiting the LFA-3/ $\mathrm{CD} 2 /$ interaction. It therefore indirectly modulates activation and proliferation of memory effector T cells [27]. As well primarily used in psoriasis, it herein has shown the most sustained effects within the group of biologic drugs [28]. Yet, due to forced but dose-dependent $\mathrm{T}$ lymphocyte depletion, a severe drop in CD4+ and CD8+ cells poses a major concern [28]. A recent trial of alefacept in diabetes type I, given in a standard dosing scheme of $15 \mathrm{mg}$ i.m. per week, showed promising results without major side effects: even though the aimed change in C-peptide was not achieved, insulin use was lowered and hypoglycemic events were decreased, indicating a possible restoration in exocrine 
Table 1. T cell targeted therapies

\begin{tabular}{|c|c|c|c|}
\hline Application/drug & Dosage & Frequency & Indication \\
\hline Topical & & & \\
\hline Cyclosporine A & $0.05 \%$ & 1 drop twice daily & Dry eye symptoms in SS \\
\hline \multicolumn{4}{|l|}{ Systemic } \\
\hline Leflunomide & $20 \mathrm{mg}$ & p.o. daily & Early pSS \\
\hline Abatacept & Weight-adapted & i.v. monthly & Early pSS \\
\hline Alefacept & $15 \mathrm{mg}$ (or still to be defined in pSS) & i.m. weekly & To be defined \\
\hline
\end{tabular}

function [29]. Therefore, in possible analogy to the underlying pathomechanism of immune-mediation by effector memory T cells, its use in pSS seems worthwhile studying-with given precautions.

Another target might be the M3 muscarinic acetylcholine receptor (M3R): being expressed in exocrine glands, it plays an important role in the exocrine secretion. Furthermore, M3R reactive T cells were detected in the peripheral blood of SS patients, indicating a possible role in the T cell activation cascade. A recent study in experimental SS-like sialadenitis indirectly showed its effects by inducing anergy of M3R reactive CD4+ T cells, hereby suppressing IFNg in vitro and reducing sialadenitis in vivo [30]. Yet, so far, clinical data are lacking.

Expression of CD40 and further CD40-related induction by IFNg has been found in cultured salivary gland epithelial cells, inducing and maintaining lymphocytic infiltration in pSS patients [31]. Identified primarily as B cell antigen, it was recognized that its ligand is expressed on activated CD4+ T cells. As interference with the CD40 pathway has shown beneficial effects in some disease models, a NOD mouse model analogous to pSS was used for proof of concept. Unfortunately, the local delivery of CD40 coupled to a human Fc domain (CD40:Fc) into the salivary glands could neither improve inflammation nor increase saliva production. The authors conclude that targeting the CD40 alone might not be helpful, and a redundancy in the CD40 pathway might be proposed [10] (Table 1).

Overall, an approach to $\mathrm{T}$ cell targeted therapy might be guided as proposed in the table.

\section{Compliance with Ethics Guidelines}

\section{Conflict of Interest}

Peter Villiger declares that he has no conflict of interest.

Sabine Adler declares that she has no conflict of interest.

Human and Animal Rights and Informed Consent

This article does not contain any studies with human or animal subjects performed by either of the authors. 


\section{References and Recommended Reading}

Papers of particular interest, published recently, have been

highlighted as:

- Of importance

1. Qin B, Wang J, Yang Z, Yang M, Ma N, Huang F, et al. Epidemiology of primary Sjögren's syndrome: a systematic review and meta-analysis. Ann Rheum Dis. 2014; $1-7$.

2. Fallah M, Liu X, Ji J, Forsti A, Sundquist K, Hemminki K. Autoimmune diseases associated with non-Hodgkin lymphoma: a nationwide cohort study. Ann Oncol. 2014;25(10):2025-30.

3. Zintzaras E, Voulgarelis M, Moutsopoulos HM. The risk of lymphoma development in autoimmune diseases: a meta-analysis. Arch Intern Med. 2005;165(20):2337-44.

4. Weng MY, Huang YT, Liu MF, Lu TH. Incidence of cancer in a nationwide population cohort of 7852 patients with primary Sjögren's syndrome in Taiwan. Ann Rheum Dis. 2012;71(4):524-7.

5. Christodoulou MI, Kapsogeorgou EK, Moutsopoulos HM. Characteristics of the minor salivary gland infiltrates in Sjögren's syndrome. J Autoimmun. 2010;34(4):400-7.

6. Meijer JM, Meiners PM, Vissink A, Spijkervet FK, Abdulahad W, Kamminga N, et al. Effectiveness of rituximab treatment in primary Sjögren's syndrome: a randomized, double-blind, placebo-controlled trial. Arthritis Rheum. 2010;62(4):960-8.

7. Nguyen CQ, Hu MH, Li Y, Stewart C, Peck AB. Salivary gland tissue expression of interleukin-23 and interleukin17 in Sjögren's syndrome: findings in humans and mice. Arthritis Rheum. 2008;58(3):734-43.

8. Yin $H$, Nguyen CQ, Samuni Y, Uede T, Peck AB, Chiorini JA. Local delivery of AAV2-CTLA4IgG decreases sialadenitis and improves gland function in the C57BL/6.NOD-Aec1Aec2 mouse model of Sjögren's syndrome. Arthritis Res Ther. 2012;14(1):R40.

9. $\quad$ Adler S, Korner M, Forger F, Huscher D, Caversaccio MD, Villiger PM. Evaluation of histologic, serologic, and clinical changes in response to abatacept treatment of primary Sjögren's syndrome: a pilot study. Arthritis Care Res. 2013;65(11):1862-8.

First study to investigate abatacept in Sjögren's syndrome on multiple levels of disease presentation including pre- and posttreatment histological changes.

10. Roescher N, Vosters JL, Lai Z, Uede T, Tak PP, Chiorini JA. Local administration of soluble CD40:Fc to the salivary glands of non-obese diabetic mice does not ameliorate autoimmune inflammation. PLoS One. 2012;7(12), e51375.

11. Deveci H, Kobak S. The efficacy of topical $0.05 \%$ cyclosporine A in patients with dry eye disease associated with Sjögren's syndrome. Int Ophthalmol. 2014;34(5):1043-8.

Well discussed usefulness of topical cyclosporine A therapy.
12. Sall K, Stevenson OD, Mundorf TK, Reis BL. Two multicenter, randomized studies of the efficacy and safety of cyclosporine ophthalmic emulsion in moderate to severe dry eye disease. CsA Phase 3 Study Group. Ophthalmology. 2000;107(4):631-9.

13. Foulks GN, Forstot SL, Donshik PC, Forstot JZ, Goldstein $\mathrm{MH}$, Lemp MA, et al. Clinical guidelines for management of dry eye associated with Sjögren disease. Ocul Surf. 2015;13(2):118-32.

14. Moscovici BK, Holzchuh R, Sakassegawa-Naves FE, Hoshino-Ruiz DR, Albers MB, Santo RM, et al. Treatment of Sjögren's syndrome dry eye using $0.03 \%$ tacrolimus eye drop: prospective double-blind randomized study. Cont Lens Anterior Eye. 2015. doi:10.1016/ j.clae.2015.04.004.

15. Hendrix DV, Adkins EA, Ward DA, Stuffle J, Skorobohach B. An investigation comparing the efficacy of topical ocular application of tacrolimus and cyclosporine in dogs. Vet Med Int. 2011;2011:487592.

16. Dalavanga YA, Detrick B, Hooks JJ, Drosos AA, Moutsopoulos HM. Effect of cyclosporin A (CyA) on the immunopathological lesion of the labial minor salivary glands from patients with Sjögren's syndrome. Ann Rheum Dis. 1987;46(2):89-92.

17. Wang K, Shi L, Yu Z, Deng Z, He A, Li S, et al. Cyclosporine A suppresses the activation of the Th17 cells in patients with primary Sjögren's syndrome. Iran J Allergy Asthma Immunol. 2015;14(2):198-207.

18. van Woerkom JM, Kruize AA, Geenen R, van Roon EN, Goldschmeding R, Verstappen SM, et al. Safety and efficacy of leflunomide in primary Sjögren's syndrome: a phase II pilot study. Ann Rheum Dis.

2007;66(8):1026-32.

19. Fox RI. Sjögren's syndrome: current therapies remain inadequate for a common disease. Expert Opin Investig Drugs. 2000;9(9):2007-16.

20. Gensburger D, Kawashima M, Marotte H, Kanitakis J, Miossec P. Lupus erythematosus with leflunomide: induction or reactivation? Ann Rheum Dis. 2005;64(1):153-5.

21. Bikker A, van Woerkom JM, Kruize AA, van der WurffJacobs KM, Bijlsma JW, Lafeber FP, et al. Clinical efficacy of leflunomide in primary Sjögren's syndrome is associated with regulation of T-cell activity and upregulation of IL-7 receptor alpha expression. Ann Rheum Dis. 2012;71(12):1934-41.

22. von Kempis J, Dudler J, Hasler P, Kyburz D, Tyndall A, Zufferey P, Villiger PM. Use of abatacept in rheumatoid arthritis. Recommendations based on current evidence. Swiss Med Wkly. 2012;142:w13581.

23. Meiners PM, Vissink A, Kroese FG, Spijkervet FK, SmittKamminga NS, Abdulahad WH, et al. Abatacept 
treatment reduces disease activity in early primary Sjögren's syndrome (open-label proof of concept ASAP study). Ann Rheum Dis. 2014;73(7):1393-6.

Good to compare to the first abatacept study.

24. Papp KA, Henninger E. Evaluation of efalizumab using safe psoriasis control. BMC Dermatol. 2006;6:8

25. Mikulowska-Mennis A, Xu B, Berberian JM, Michie SA. Lymphocyte migration to inflamed lacrimal glands is mediated by vascular cell adhesion molecule-1/alpha(4)beta(1) integrin, peripheral node addressin/l-selectin, and lymphocyte functionassociated antigen-1 adhesion pathways. Am J Pathol. 2001;159(2):671-81.

26. Prater EF, Day A, Patel M, Menter A. A retrospective analysis of 72 patients on prior efalizumab subsequent to the time of voluntary market withdrawal in 2009. J Drugs Dermatol. 2014;13(6):712-8.

27. Crow JM. Therapeutics: silencing psoriasis. Nature. 2012;492(7429):S58-9.
28. Papp KA. The long-term efficacy and safety of new biological therapies for psoriasis. Arch Dermatol Res. 2006;298(1):7-15.

29. Rigby MR, DiMeglio LA, Rendell MS, Felner EI, Dostou JM, Gitelman SE, et al. Targeting of memory T cells with alefacept in new-onset type 1 diabetes (T1DAL study): 12 month results of a randomised, double-blind, placebo-controlled phase 2 trial. Lancet Diabet Endocrinol. 2013;1(4):284-94.

30. Asashima $\mathrm{H}$, Tsuboi $\mathrm{H}$, Takahashi $\mathrm{H}$, Hirota T, Iizuka $\mathrm{M}$, Kondo $\mathrm{Y}$, et al. The anergy induction of M3 muscarinic acetylcholine receptor reactive CD4+ T cell suppresses experimental sialadenitis like Sjögren's syndrome. Arthr Rheumatol. 2015. doi:10.1002/art. 39163.

31. Dimitriou ID, Kapsogeorgou EK, Moutsopoulos HM, Manoussakis MN. CD40 on salivary gland epithelial cells: high constitutive expression by cultured cells from Sjögren's syndrome patients indicating their intrinsic activation. Clin Exp Immunol. 2002;127(2):386-92. 